\title{
Vietnamese Consumers Search For Information Online: Some Research Hypotheses
}

\author{
Phong Bach Thanh \\ Lac Hong University \\ Dong Nai Province, Vietnam
}

\begin{abstract}
This study provided the proposed hypotheses to encourage researcher to do more study to gain knowledge of online information search behavior of Vietnamese customer. In online customer context, some psychology theories have proved its power in explaining customer action and there were lot of empirical research in the world supported this viewpoint. In addition, due to information available on the Internet, customers are willing to search product or service information online and this action is likely to be habitual behavior. Habit is special psychology construct and thus the empirically study to exam the role of this factor is pragmatic and urgent.
\end{abstract}

Keywords: TPB, TIB, habit, online, information search behavior

\section{Introduction}

Vietnam had 68,000,000 Internet users, more than $70 \%$ of the population using the Internet according to Internet World Stats, 2018. So, online customer behavior is interesting subject to many researchers in Vietnam.

Information search is an important part of the decision process for most consumers considering the purchase (Punj and Staelin, 1983). According to the survey of Net Index (Yahoo) in 2011, more than 96\% of surveyed people used search engine as the most popular online activity. In addition, the development of e-commerce and online shopping, consumer's habits have changed in both ways of buying and shopping places (Liu and Forsythe, 2011). For example, to buy something, consumers have to go to a market, a store or a mall to conduct a transaction, but now they can update information search and order online directly with the supplier via internet. In Customer Barometer research of Google in 2015, they pointed 70\% Vietnamese customers used search engine before making purchase decision.

On the other hand, due to the immense amount of information available, web search engines have revolutionized the process by which individuals seek information. The majority of consumers participate in web searches during one or more stages of purchasing (Vuylsteke et al., 2010).

Seeking information online can be done in many different ways, depending on each individual, each situation.For Vietnamese customer, there is a question: what are the factors that motivate customer to search for goods and services information? Finding the answer for this question will contribute to improve the understanding of Vietnamese consumer behavior.

In a literature review study, Cummins et al. (2014) concluded that there were very few researches on consumers' online information search behavior. These authors pointed that only 72 studies out of 942 studies from $1993-2012$ were conducted worldwide. Moreover, they argued that the conceptualization and testing of empirical models that link to consumer behavioral theories in online context was still exploratory. Therefore, more research is needed to understand online information search behavior. A large knowledge gap also exists in understanding of the psychological premises that motivate consumers to seek and promote consumers to shop online. In other words, the psychosocial aspects have not been given enough attention by the researchers to explain this kind of behavior.According to Salste (1996), the Internet experience was positively correlated with the amount of time spent online and the experienced users used the Internet more often and had longer sessions. For experienced users, the Internet is a habit. However, this raises an additional question: "Whether consumers' online search behavior is affected by habits".

We suppose that consumers' behavior of seeking information online is not fully understood. Therefore, this study will contribute to the theoretical basis as well as providing a more complete view of the motivations for Vietnamese consumers to search for information online. The author proposes some research hypotheses in order to encourage more research on consumers' behavior of seeking information online.

\section{Conceptual Framework}

\subsection{Theoretical Background}


According to Schmidt and Spreng (1996), there were nearly 60 factors that were found to explain consumers' prepurchase information behavior. These factors could be divided into three dimensions: environmental factors, situational factors and consumer characteristics. Environmental factors related to the difficulties of selection, the number of alternative products, the complexity of the options; Situational factors related to satisfaction, time constraints, and perceived risk. Consumer characteristics related to education, personal knowledge and engagement.

Schmidt and Spreng (1996) suggested these 60 factors have been approached by researchers in three main ways. The first way was the psychological approach and motivation of each individual involved in search behavior. The measurement variables related to each person's beliefs, attitudes, and involvement towards behavior or towards products (Beatty and Smith, 1987; Duncan and Olshavsky, 1982). The second one was the economic approach, using a cost-benefit framework to search for information, which means consumers evaluate the costs and benefits of searching when making search decision. The third was an approach involving consumer information processing, focusing on individual memory and consumer cognitive theory when processing information. Due to the wide scope of the topic, in this study, we only approach at the psychological level, motivation and consumer engagement to search for information online.

\subsubsection{Theory of reasoned action (TRA)}

According to Fishbein and Ajzen'sTheory of Reasoned Action (TRA), behavior is predicted or explained by the intention to perform. The relationship between intention and behavior had been experimentally tested in numerous studies and in various fields (Ajzen, 1988; AjzenandFishbein, 1980; Canary andSeibold, 1984; Sheppard et al., 1988, quotedin Ajzen, 1991, p. 186). Intention is considered to include motivational factors that affect the behavior of the individual; these factors indicate the level of willingness or effort that each individual will spend to perform the behavior. The two components predict behavioral intentions are personal attitude and subjective norms:

1. An individual's attitude to the behavior is understood as an individual's view of behavior as good or bad, pleasant or unpleasant, etc. Personal attitude to the behavior is measured by belief of the outcomes of the behavior.

2. Subjective norm is social stereotypes of important people that affect a person's behavior. Subjective norm is measured by the view of a specific person or group of people whether the individual should or should not behave and that action is consistent with what they think.

TRA model had been widely apply and had made accurately predictions for a variety of behaviors. Since Fishbein and Ajzen (1975) developing the model, many researchers have argued that the accuracy of the model could increase significantly if some new factors were added. However, these suggestions only lead to experimental limitations.

\subsubsection{Theory of planned behavior (TPB)}

A few years later, Ajzen (Schifter and Ajzen, 1985; Ajzen, 1988) expanded the theory of reasoned action into a theory of planned behavior by adding perceived behavioral control (PBC). Perceived behavioral control is considered a person's perception that the behavior is easy or difficult to perform. According to Ajzen, even if attitude and subjective norm support for a specific action but the belief that action is difficult to perform, it may cause the person to intend not to do it (Trafimow, 2000). This factor was argued to increase the prediction of an individual's intention and behavior in case of the behavior was not entirely under the control of the individual (Towler and Shepherd, 1991-1992).

\subsubsection{Theory of interpersonal behavior (TIB)}

Triandis (1980) proposed a complex theory that included elements mentioned in theory of reasoned action (TRA) and other factors. Emotional factor refer to an individual's feelings, joys, depression or discontent related to the specific behavior being addressed. These emotions could be positive (pleasant) or negative (unpleasant) and strong or weak (Triandis, 1977). Moreover, Triandis suggested that one of the causes of behavior was because of the repetition of past actions and certain learning behaviors. In other words, one of the causes of behavior was because of the "habit" of doing it.

The importance of habit was further considered when some researchers had found that past behavior was a good predictor of future intention to behave (Conner and Armitage, 1998; Orbell, Hodgkins and Sheeran, 1997; Ouelette and Wood, 1998).

\subsection{Compare TPB and TIB}

TPB and TIB are similar, both include individual's attitude and social norms which influence their intentions to act in particular action, and both consider that the behavior may be influenced by environmental factors and individual is not always voluntary to perform. However, there are three main differences (see Table 1). Firstly, TIB suppose that habits would have a significant influence on the actual behavior of individuals. TIB even suggests that for many behaviors, habits may be more important than intention in determining an individual's actions. 
Second, TPB only considers the cognitive aspect of attitude in building individuals' attitude manner, while TIB considers both emotional and attitude aspects: emotional aspect is assessed through the concept of "affect", while the cognitive aspect is assessed through the concept of "attitude". TIB shows that affect and attitude factors usually create independent information and therefore should be considered as two separate concepts. In addition, the concept of "attitude" of TPB is defined similarly to the concept of "perceived consequences" of TIB - both related to expected results. Third, while TPB's "perceived behavioral control" and TIB's "facilitating conditions" are nearly equivalent, TPB believes that perceived behavioral control predicts an individual's intention and may apply to predict behavior within some situations. On the other hand, TIB believes that facilitating conditions affect directly to behavior rather than through intention, because even if the intention has been established to perform the behavior, but the environment does not support its action, the behavior may not be performed.

Table 1: Compare TPB and TIB

\begin{tabular}{cc}
\hline Concepts in TPB & Concepts in TIB \\
\hline None & Habits \\
None & Affect \\
Attitude & Perceived Consequences \\
Subjective Norms & Social factors \\
Perceived Behavioral Control & Facilitating Conditions \\
Intention & Intention \\
Behavior & Behavior \\
\hline
\end{tabular}

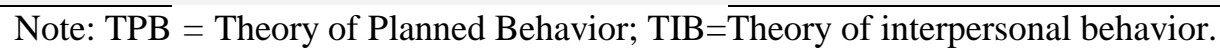

\section{Research Hypotheses}

\subsection{Online Information Search (OIS)}

Information search here is understood as seeking information about goods and services. According to Nelson (1970) finding information includes any way to evaluate options under two restrictions:

1. Consumers must check options;

2. That inspection must occur before purchasing a brand. Consumers can search for quality as well as price, and if the purchase price is low enough, any other costly search process will be excluded.

Nelson's information search definition was correct at that time, but the are some limitations now such as: (a) at that time, the Internet did not appear, information was not connected as globally as it is today, (b) the cost of finding information online is currently very low.

According to Peterson and Merino (2003), consumer information search behavior includes what is called internal search and external search. By this definition, searching for internal information relates to memory and occurs before searching for external information. Chiang (2006) inherited this definition and argued that information search is a stage in the decision-making process in which consumers actively collect and use information from many internal and external sources to make better purchase decision. Chiang (2006) also suggested that in order to find information online from websites, consumers have several ways to locate websites: (1) via search engines, (2) entering the website address they want to search and (3) via browser support tools.

Therefore, the definition of online information search is understood as the definition of Nelson (1970) and Chiang (2006). Online information search is the way for consumers to check their choices and is a stage in the decisionmaking process in which consumers actively collect and use information on the Internet through search engine such as Google, Bing, Baidu, etc. or through the vendor's website / commercial platform to make better purchase decision.

According to Yalçın and Köse (2010), a search engine is a type of software that collects data about websites on the Internet. The data is collected includes the URL of the website, keywords or keyword groups that determine the content of the website, the source structure of the website and the links provided on the website. The role of search engines is extremely important in displaying relevant results to users by algorithms. Even Gordon and Pathak (1999) suggested that access to information based on the Internet would collapse without these search engines.

\subsection{TPB Components in Research Model}

It can be said that the theory of reasoned action (TRA) and the theory of planned behavior (TPB) were used by many researchers to explain online information search behavior (Shim et al., 2001; Watchravesringkan and Shim, 2003; 
Kim et al., 2004; Kim and Park, 2005; Seock and Norton, 2007; Vazquez and Xu, 2009; Chang et al., 2009). Moreover, TRA and TPB have been considered as dominant theories in the study of online human behavior (Cheung et al., 2005; McCormick and Livett, 2012).

The TPB model is considered to be more optimal with TRA in predicting and explaining consumer behavior in the same research context. In study of predicting unethical behavior, Chang (1998) had applied both TRA and TPB theory and the result showed that the TPB model explained customer behavior better than the TRA model. Chang et al. (2009) also tested these two theoretical models and the result showed that TPB explained customer online information search behavior better than TRA.

Since TPB is used as the baseline model, we also expect the following TPB hypothesized relationships in the context of online information search.

\subsubsection{The relationship between attitude towards online information search behavior and intention to search for information online}

According to Ajzen (1991), an individual's attitude towards that behavior is understood as an individual's view of behavior as good, bad, pleasant or unpleasant, etc. In online search context, the attitude towards online information search is understood as the act of finding information online is beneficial or not beneficial, satisfied or dissatisfied, etc. and is measured by the results of the behavior.

Shim et al. (2001) have demonstrated the relationship between consumer attitude to search intention and purchase intention based on TPB framework. Their findings showed that customer attitude had a positive impact on the intention to use the Internet to find information. The study of Watchravesringkan and Shim (2003) and Chang et al. (2009) also showed similar results.

Kim and Park (2005) stated that when a consumer had a positive attitude towards a retailer, he or she was more likely to be willing to seek product information from the retailer. Results of Kim and Park research showed that attitude towards online stores played the important role in predicting the intention to find information online. Similarly, Seock and Norton (2007) argued that the more positive consumer attitude toward retailers' websites, the stronger their intention to use those sites to find product information. Seock and Norton results showed that consumer attitude had a positive and direct influence on the intention to find information. Thus, the proposed hypothesis is:

H1. Attitude has a positive impact on intention to search for information online.

\subsubsection{The relationship between subjective norms and intention to search for information online}

According to Ajzen (1991), subjective norms are the social stereotypes of important people which affect a person's behavior. In online search context, subjective norms are measured by the view of some people or a group whether individuals should or should not search information online and whether this behavior is appropriate or not with people opinion.

Chang et al. (2009) suggested that subjective norms expressed individual's awareness and motivation based on relevant references, thereby affecting the intention to find information online. Chang et al (2009) showed subjective norms had a positive and direct impact on the intention to search information online. However, this factor was the weakest one that influence on the online information search intention.

Meanwhile, Shim et al. (2001) did not find any effect of this factor on the intention to search information online. Therefore, we also suggest to clarify the influence of this factor, so the proposed hypothesis is:

H2. Subjective norms have a positive impact on intention to search for information online.

\subsubsection{The relationship between intention and online information search behavior}

For TRA and TPB theories, the behavior is predicted or explained by the intention to perform that behavior. Intention is considered to include motivational factors that affect individual behavior; These factors indicate the level of willingness or effort that each individual will spend to perform the behavior. The strong relationship between intention and behavior in reasoned action and planned behavior theories had been experimentally tested in numerous studies in many fields. In online information search context, intention to search for information online includes motivational factors that influence the search behavior through an online network environment.

Klein (1998) who proposed an interactive model, also suggested that the motivation to search information online should be seen as an important predictor of search behavior. In particular, the intention would affect the search experience thereby positively affecting customer search behavior.

Although the TRA and TPB theoretical framework have been recognized by many researchers to be effective in predicting an individual's behavior, and the behavior is predicted by intention. 
But it does not mean that individual has intention to seek information online and then they will definitely conduct online information search. Although the relationship between intention and behavior is very strong but some behaviors are not explained by intention (Chang et al., 2009).

In online search context, the author also want to encourage researchers should test the relationship between online information search intention and behavior. Therefore, the proposed research hypothesis is:

H3. Intention has a positive impact on online information search behavior.

\subsubsection{The relationship between of perceived behavioral control, intention and online information search behavior}

In customer online search context, perceived behavioral control (PBC) is considered to be a person's perception that online information search behavior is easy or difficult to perform. According to Ajzen (1991), PBC play a dual role in TPB. First, it is co-determinants of intention along with attitude and subjective norms. Second, together with intention, it is co-determinants of behavior.

Shim et al. (2001) suggested that shopping on the Internet required consumers to have the skills and resources. More specifically, individuals had to own a computer or had to have authority to access. The results of Shim research also proved that PBC factor had positively impact on thee intention to search information online.

Kim and Park (2005) suggested that people who found easier and more confident in shopping on the internet were more likely to use the internet to search for product information. More specifically, Kim and Park (2005) argued that the greater the individual's ability to control the behavior, the greater the intention to seek product information through online stores. The results of their study had proved that PBC had a positive influence on the intention to find information online

Similarly, Chang et al. (2009) suggested that when users have relevant skills and resources, PBC was a key determinant to explain their intention to seek information in an online environment. Chang's results also showed that the role of this factor was important in predicting customer online information search intention. Therefore, the proposed research hypothesis is:

H4. Perceived behavioral control has a positive impact on intention to search for information online.

Ajzen (1991) pointed out PBC factor would predict an individual's intention and could be applied to predict behavior in some situations. Shim et al. (2001) also suggested that if individuals found difficulty to search online, PBC would create an obstacle for finding information online. Moon (2004) proposed that the level of consumer knowledge would affect the efficiency of information retrieval via the Internet and was likely to affect to consumers seeking information on the Internet. Therefore, we also suggest to clarify the influence of this factoron search behavior, so the proposed hypothesis is:

H5. Perceived behavioral control has a positive impact on online information search behavior.

\subsection{The Role of Habit to Online Information Search}

Moon (2004) argued that consumers lifestyle would make them use the Internet and search information online more usually. Moreover, nowadays customers tend to repeat their search behavior (daily, weekly) due to the rapid development of the global Internet and the information available online. According to Salste (1996), once consumers had experience to use the Internet and the behavior was repeated frequently, that behavior would be a habit.

\subsubsection{Online information search habit definition}

The concept of habit could be traced back to James (1890), who probably first pointed out the importance of habit in everyday life:

"There is no more miserable human being than one in whom nothing is habitual but indecision, and for whom the lighting of every cigar, the drinking of every cup, the time of rising and going to bed every day, and the beginning of every bit of work, are subjects of express volitional deliberation (p. 122)".

Verplanken et al. (1997) defined habits as "learned sequences of acts that become automatic responses to specific situations which may be functional in obtaining certain goals or end states".

In online consumer context, Gefen (2003) defined "consumer habits as their previous trend patterns and preferences". Limayem and Hirt (2003) defined "habit refers to the non-deliberate, automatically inculcated response that individuals may bring to the use of information systems".

Limayem et al. (2007) suggested some interesting points of how developing habits. It required a minimum of weekly repetition or practice and in order to establish a habit, it also need stable context (Ouelette and Wood, 1998). He also mentioned the satisfactory experiences make people tend to repeat the action again. 
So according to Limayem et al. (2007), there were three elements for habit formulation and he defined habits as "the extent to which people tend to perform behaviors automatically because of learning.

Ortiz de Guinea and Markus (2009) defined habits as "well-learned action sequences may be activated by environmental cues and then repeated without conscious intention".

Chiu et al. (2012) defined "habits in the context of online shopping as the extent to which shoppers tend to shop online automatically without thinking".

We agree and adopt Limayemand Ortiz de Guineadefinition as "habit of searching information online is the extent to which people tend to take action (search) automatically, unconscious because this action has been learned. Defined in this way, habit is relatively less likely to overlap with intention concept (Trafimow, 2000) and thus habit can be seen as a factor to predict online information search behavior directly.

\subsubsection{Habit affect directly to online information search}

A group of researchers consideredthat habit and intention are two independent concepts that play a predictive role in actual behavior. Triandis $(1977,1980)$ was probably the first supporter of this view and developed an interpersonal behavioral model which separated from Ajzen's reasoned action theory, but had some factors in common. In particular, habit along with intention, were used in direct prediction of behavior. Although Triandis (1980) argued that the key concept of habit was not controlled by consciousness, the measures he suggested which related to the frequency of repeating past behaviors and he also did not combine this concept of habit in automatic direction.

In predicting online behavior of consumers, Limayem and Hirt (2003) modelized habit affected directly to website usage. Their results confirmed that habit was found to significantly influence actual behavior along with intention.

Escobar-Rodríguez and Carvajal-Trujillo (2014) modelized habit as a direct predictor of online user behavior. The results showed that habit played an important predictor for online air ticket buying behavior. Similarly, Osatuyi and Turel (2018) showed habit had a positive impact on social networks usage. In online search context, we also accept this viewpoint that habit makes direct influence on online information search behavior. Therefore, the proposed research hypothesis is

H6. Habithas a positive impact on online information search behavior.

\section{Conclusion}

This paper enconrages researchers to testthetheory of reasoned action (TRA) and the theory of planned behavior (TPB) framework to explain consumers'online information search behavior. However, there is one of the biggest restrictions on TRA theory is the fact that it only applies to intentional behavior. Sheppard et al. (1988) disagreed with this theory by arguing that there is definitely a difference between what individuals expected and what they actually do. For TPB, Ajzen (2006) pointed out that PBC involves an individual's perception of the ability to perform behavior in a certain way.If the perception is correct, then it will reflect real control over behavior. Ajzen (2006) also acknowledged that there were some problems related to PBC measurement because individuals could not fully understand the situations that would occur to self-awareness and control the implementation of behaviors.

The proposed hypothese focus on habit concept and distinction between habit, intention and PBC constructs and how these constructs contribute to predict online information search behavior in a developing country like Vietnam. There is no evident so far but the author would like to invite reseachers pay more attention on habit constructs, esspecially its relation to online search behavior.

Although Triandis (1980) developed interpersonal behavior theory (TIB) separated from the reasoned action theory (TPB) of Ajzen (1991) and argued that habit along with intention, influence directly to behavior. However, with the fame and accurate prediction of many diverse behaviors in many different fields and contexts, TPB was preferred by researchers over TIB.

In the field of online consumer behavior, there were many authors pointed that habit factor was an important motivator (Gefen, 2003; Limayem et al., 2007; Chiu et al., 2012) in predicting online consumer behavior. Despite, most of researchers conceptualized habit as automatic behavior, these authors believed that habit only affected to intention or habit was a moderator between intention and behavior relationship. This study is one of very few studies in Vietnam that propose the role of habits in case of habit is direct factor to online consumer behavior, along with intention and PBC. 


\section{References}

Ajzen, I. and Fishbein, M. (1980). Understanding Attitudes and Predicting Social Behavior. Prentice-Hall, Englewood Cliffs, NJ.

Ajzen, I. (1988). Attitudes, Personality, and Behavior. Open University Press, Milton Keynes, UK.

Ajzen, I. (1991). The theory of planned behavior. Organizational behavior and human decision process, 50, 179-211.

Ajzen, I. (2006). Perceived Behavioral Control, Self-Efficacy, Locus of Control, and the Theory of Planned Behavior. Journal of applied social psychology, 32(4), 665-683.

Beatty, S. A., and Smith, S. M. (1987). External search effort: an investigation across several product categories. Journal of Consumer Research, 14 (June), 83-95.

Canary, D. J. and Seibold, D. R. (1984). Attitudes and behavior: An annotated bibliography. New York: Praeger.

Chang, M. K. (1998). Predicting unethical behavior: a comparison of the theory of reasoned action and the theory of planned behavior.Journal of Business Ethics, 17, 1825-1834.

Chang, C. C., Lin, C. Y., Chen, Y. C., and Chin, Y. C. (2009). Predicting information-seeking intention in academic digital libraries. The Electronic Library, 27(3), 448-460

Cheung, C.M.K., Chan, G.W.W. and Limayem, M. (2005). A critical review of online consumer behavior: empirical research. Journal of Electronic Commerce in Organizations, 3(4), 1-19.

Chiang, K. (2006). Clicking instead of walking: Consumers searching for information in the electronic marketplace. The Information Society for the Information Age Bulletin, 35(5).

Chiu, C. M., Hsu, M. H., Lai, H., and Chang, C. M. (2012). Re-examining the influence of trust on online repeat purchase intention: The moderating role of habit and its antecedents. Decision Support Systems, 53(4), 835845.

Conner, M., and Armitage, C. J. (1998). Extending the theory of planned behavior: A review and avenues for further research. Journal of Applied Social Psychology, 28, 1429-1464.

Cummins, S., Peltier, J. W., Schibrowsky, J. A. and Nill, A. (2014). Consumer behavior in the online context. Journal of Research in Interactive Marketing, 8(3), 169-202.

Duncan, Calvin P. and Olshavsky Richard W. (1982). External search: The role of consumer beliefs. Journal of Marketing Research, 19 (Feb), 32-43.

Escobar-Rodíguez, T., and Carvajal-Trujillo, E. (2014). Online purchasing tickets for low cost carriers: an application of the unified theory of acceptance and use of technology (UTAUT) model. Tourism Management, 43(August), 70-88.

Fishbein, M., and Ajzen, I. (1975). Belief, Attitude, Intention and Behavior: An Introduction to Theory and Research. Addison-Wesley Publishing, Reading, MA.

Gefen, D. (2003).TAM or just plan habit: a look at experienced online shoppers. Journal of End User Computing, 15(3), 1-13.

Google Consumer Barometer (2015, June 17). What online sources did people use to make a purchase decision? Google, Vietnam. Retrieved July 15 th 2019 from https://www.slideshare.net/hirukajean/google-consumerbarometer-2015-report-vietnam

Gordon, M., and Pathak, P. (1999). Finding information on the World Wide Web: The retrieval effectiveness of search engines. Information Processing and Management, 35(2), 141-180.

Internet World Stats (2018, December 30). Asia Internet Use, Population Data and Facebook Statistics December 2018. Retrieved July $16^{\text {th }}, 2019$ from https://www.internetworldstats.com/stats3.htm\#asia

James, W. (1890).The Principles of Psychology. Henry Holt \& Co., New York.

Kim J .I., Lee H.C. and Kim H.J. (2004). Factors Affecting Online Search Intention and Online Purchase Intention. Seoul Journal of Business, 10(2), 176-184.

Kim, J. and Park, J. (2005). A consumer shopping channel extension model: attitude shift toward the online store. Journal of Fashion Marketing and Management, 9(1), 106-121.

Klein, L.R. (1998). Evaluating the potential of interactive media through a new lens: search versus experience goods. Journal of Business Research, 41(3), 195-203.

Limayem, M., and Hirt, S. G. (2003). Force of Habit and Information Systems Usage: Theory and Initial Validation. Journal of the Association for Information Systems, 4, 65-97.

Limayem, M. and Hirt, S. G. and Cheung, C.M.K. (2007). How habit limits the predictive power of intentions: the case of IS continuance. MIS Quarterly, 31(4), 705-737.

Liu, C.L. and Forsythe, S. (2011). Examining drivers of online purchase intensity: moderating role of adoption duration in sustaining post-adoption online shopping. Journal of Retailing \& Consumer Services, 18(1), 101-109. 
Moon, B. J. (2004). Consumer adoption of the internet as an information search and product purchase channel: some research hypotheses.

McCormick, H. and Livett, C. (2012). Analysing the influence of the presentation of fashion garments on young consumers' online behavior. Journal of Fashion Marketing and Management, 16(1), 21-41.

Nelson, P. (1970). Information and consumer behavior. Journal of Political Economy, 78(2), 311-329.

Orbell, S., Hodgkins, S.and Sheeran, P. (1997). Implementation intentions and the theory of planned behavior. Personality and Social Psychology Bulletin, 23, 953-962.

Ortiz de Guinea, A., and Markus, M. L. (2009). Why Break the Habit of a Lifetime? Rethinking the Roles of Intention, Habit, and Emotion on Continuing Information Technology Use. MIS Quarterly, 33(3), 433-444.

Osatuyi, B., Turel, O. (2018). Tug of war between social self-regulation and habit: Explaining the experience of momentary social media addiction symptoms. Computers in Human Behavior, 85, 95-105.

Ouelette, J.A. and Wood, W. (1998). Habit and intention in everyday life: The multiple processes by which past behavior predicts future behavior. Psychological Bulletin, 124, 54-74.

Peterson, Robert A., and Maria C. Merino (2003).Consumer Information Search Behavior and the Internet.Psychology and Marketing, 20 (2), 99-121.

Punj, Girish N. and Richard Staelin (1983). A model of consumer information search behavior for new automobiles. Journal of Consumer Research, 9 (March), 366-380.

Salste, Tuomas (1996). The Internet as a mode of non-store shopping.Retrieved July $17^{\text {th }}$, 2019 from http://www.aivosto.com/vbq5/study.html

Schifter, D. E. and Ajzen, I. (1985). Intention, perceived control, and weight loss: an application of the theory of planned behavior. Personality Social Psychol, 49, 843-51.

Schmidt, J. B. and Spreng, R. (1996). A proposed model of external consumer information search. Journal of the Academy of Marketing Science, 24, 246-256.

Seock, Y and Norton, M., (2007). Attitude toward internet web sites, online information search, and channel choices for purchasing. Journal of Fashion Marketing and Management, 11 (4), 571 - 586.

Sheppard, B. H., Hartwick, J. and Warshaw, P. R. (1988). The theory of reasoned action: A metaanalysis of past research with recommendations for modifications and future research. Journal of Consumer Research, 15, 325-343.

Shim, S., Eastlick, M.A., Lotz, S.L., Warrington, P. (2001). An online prepurchase intentions model: the role of intention to search. Journal of Retailing, 77(3), 397-416.

Towler, G., and Shepherd, R. (1991-1992). Modification of Fishbein and Ajzen's Theory of Reasoned Action to predict to chip consumption. Food Quality and Preference, 3(1), 37-45.

Trafimow, D. (2000). Habit as Both a Direct Cause of Intention to Use a Condom and as a Moderator of the AttitudeIntention and Subjective Norm-Intention Relations. Psychology and Health, 15(3), 383-393.

Triandis, H. C. (1977). Interpersonal Behavior. Brooks/Cole, Monterrey, CA.

Triandis, H. C. (1980). Values, attitudes, and interpersonal behavior. Nebraska Symposium on Motivation, University of Nebraska Press, Lincoln.

Vazquez, D., and Xu, X. (2009). Investigating linkages between online purchase behaviour variables. International Journal of Retail \& Distribution Management, 37(5), 408-419.

Verplanken, B., Aarts, H., and van Knippenberg, A. (1997). Habit, Information Acquisition, and the Process of Making Travel Mode Choices. European Journal of Social Psychology, 27(5), 539-560.

Vuylsteke, Alexander, Zhong Wen, Bart Baesens, and Jonas Poelmans (2010). Consumers' Search for Information on the Internet: How and Why China Differs from Western Europe. Journal of Interactive Marketing, 9, 309-331.

Watchravesringkan, K. and Shim, S. (2003). Information search and shopping intentions through internet for apparel products. Clothing and Textiles Research Journal, 21 (1), 1-7.

Yalçın, N. and Köse, U. (2010). What is search engine optimization: SEO? Procedia - Social and Behavioral Sciences, 9, 487-493.

Yahoo Kantar Media Net Index (2011, September 18). Net Index 2011 for Vietnam.Yahoo Kantar Media, Vietnam. Retrieved July $17^{\text {th }}, 2019$ from https://www.slideshare.net/johnyvo/vn-net-index-2011-yahoo-kantar-media 